\title{
Tendências latino-americanas da política social pública no século 21
}

\author{
Aldaiza Sposati \\ Pontifícia Universidade Católica de São Paulo (PUC-SP)
}

Tendências latino-americanas da política social pública no século 21

Resumo: Este texto tem por objetivo examinar tendências das políticas sociais latino-americanas para o século 21 a partir de sua gênese e de seu desenvolvimento marcados, ao final do século 20, pelas contingências impostas pelo neoliberalismo. O enfrentamento da pobreza e o confronto com as desigualdades sociais constituem, neste novo século, dois paradigmas em oposição. Considera-se que essa dualidade tende a fortalecer a existência de sistemas sociais paralelos que fragilizam o alcance de padrões igualitários dos direitos sociais a todos os cidadãos.

Palavras-chave: Políticas sociais. Políticas públicas latino-americanas. Direitos sociais, Democratização. Universalismo.

\section{Trends in Latin American Social Policy in the 21st Century}

Abstract: The purpose of this text is to examine trends in Latin American social policy in the 21st century based on their genesis and development in the late 20th century, under contingencies imposed by neoliberalism. The confrontation with poverty and social inequalities constitute, in this new century, two opposing paradigms. The paper considers that this duality tends to strengthen the existence of parallel social systems that weaken the scope of egalitarian standards of social rights for all citizens.

Key words: Social policies. Latin American public policies. Social rights, Democratization. Universalism. 


\section{Introdução}

Desenhar, ainda que a traços largos, as configurações da política social na América Latina para o século 21, objetivo deste artigo, estabelece duas perspectivas. Supõe abordar, de um lado, o estatuto herdado das políticas sociais latino-americanas do último quartil do século 20, com a superação, ou não, dos problemas que nele se instalaram e, de outro, analisar as tendências de um novo estatuto em sua reconfiguração.

As políticas sociais públicas latino-americanas no século 21 têm duplo desafio: superar suas heranças do século 20, sob a conjuntura do modelo neoliberal, e confrontar as desigualdades sociais e econômicas de forma a garantir a universalidade e a equidade de direitos humanos e sociais, tornando-os alcançáveis para os estratos que permanecem precarizados em suas condições de vida, trabalho e cidadania.

É preciso tornar claro que não parto da concepção da política social como mera estratégia do capital sobre o trabalho e via de mão única. A complexidade histórica exige a incorporação das lutas travadas entre sujeitos sociais representantes de interesses de classes, mesmo que as forças contrahegemônicas possam oscilar, sob diferentes conjunturas, em seu protagonismo para configurar as políticas sociais públicas. Não enxergo ou conceituo uma política social sob a leitura de uma armadilha do capital sobre o trabalho. Ainda que, na sociedade de mercado, ocorra hegemonia dos interesses do capital, nela ocorre, também, a contra-hegemonia do trabalho e das forças sociais que lutam por novos ganhos na agenda do Estado, incluindo novas responsabilidades públicas em direção à consolidação de seus direitos. A política social é uma construção histórica e, como tal, não está fadada a ser capturada por um dos lados em que se posicionam os sujeitos sociais históricos, mas sim, e desde que colocada em contexto democrático, em ter disputados seus meios e fins entre os projetos sociais desses sujeitos conscientes e ativos.

Com certeza essas lutas não alcançam ganhos plenos, embora signifiquem possibilidades de avanços no âmbito dos direitos humanos, sociais e da cidadania.

Parto da afirmação que, nas duas últimas décadas do século 20, as lutas sociais contra-hegemônicas buscaram estabelecer novo formato dos meios e modos de relação entre Estado e sociedade, principalmente quanto à presença da voz e decisão dos grupos populares e à inclusão de novas responsabilidades sociais públicas pelo Estado. Centraram-se mais no processo de derrubada do autoritarismo e da privatização no interior do Estado do que, propriamente, no alcance da universalização e equidade de direitos humanos e sociais. Estes direitos permanecem mais avançados "no papel" do que em sua efetivação concreta. A efetivação de direitos humanos e sociais, em muitos países latino americanos, é marcada pela distância entre o real e o texto legal. $\mathrm{O}$ pacto que propiciou o avanço no texto legal não atingiu valores conservadores e avessos à universalização e a equidade de direitos. Esta luta ainda mobiliza ações de grupos da sociedade e de agentes institucionais.

Durante as últimas décadas do século 20, o confronto com o formato autoritário do Estado centrou forças em luta na busca de efetivar novas relações democráticas e participativas na gestão estatal. No século 21, colocam-se novos campos de confronto para o enfrentamento das desigualdades sociais, econômicas, jurídicas, culturais, políticas e a constituição da universalidade de acesso que respeite as diferenças e, com ela, a construção do direito à equidade.

\section{Registros preliminares}

A construção das políticas sociais na América Latina percorre trajetória histórica diversa da Europa Central e sua regulação social do pós-Segunda Guerra. Ressalve-se que o continente europeu possui configurações histórico-sociais diferenciadas entre seus países, que se refletem na formatação das suas políticas sociais. A Europa do Norte, os países escandinavos, e os países centrais, como Inglaterra e França, desenvolveram proposta unificada de respostas sociais conhecidas como welfare state, cuja aplicação foi diferenciada em outros países da Europa Central. A análise paradigmática de EspingAndersen (1990) sobre os regimes europeus de welfare distingue-os em três tipologias.

Na América Latina, as políticas sociais foram sendo incorporadas de forma fragmentada e setorial. Há forte distinção entre os países quanto às responsabilidades estatais para garantir a toda a população direitos humanos e sociais.

Registros de Mesa-Lago (2004) agregam as iniciativas em política social dos 20 países de região ${ }^{1}$ em três períodos:

a) desde os anos 1920, despontam cinco países pioneiros, que desenvolveram medidas sociais nacionais, em decorrência da industrialização das demandas de trabalhadores urbanos: Chile, Uruguai, Brasil, Argentina e Cuba;

b) nos anos 1940, figuram entre os países intermédios, cujas medidas foram incidentes em concomitância às iniciativas europeias, orientadas pelos princípios do Relatório Beveridge: Costa Rica, Equador, Peru, Panamá, Paraguai, Colômbia, México, Venezuela. Na Costa Rica, foi fortalecido o padrão universal das políticas sociais, mas a tendência nos países foi de ins- 
talação de sistemas paralelos de atenção, isto é, o sistema focalizado ao lado do universal;

c) ao final dos anos 50 e início de 60, destacamse seis países considerados de tardia iniciativa, onde as políticas sociais aparecem, de forma residual e excludente: República Dominicana, El Salvador, Guatemala, Nicarágua, Haiti, Honduras.

Franzoni (2005), em estudo sobre as políticas sociais nos países latino-americanos, concluiu pela presença de três tipos de regimes de bem-estar social na região. Levou em conta princípios de Esping-Andersen (1990) como: a desmercadorização, a desfamiliarização e os seus efeitos na estrutura social.

O primeiro regime é de caráter estatal, nele o Estado é provedor da maior parte dos recursos voltados para serviços universais. Costa Rica e Uruguai concretizam esse modelo. Os dois são países com menor índice de desigualdade econômica na região, com coeficientes Gini menores a 0,50. Esse modelo vem sendo fragilizado pela ampliação da presença do mercado na provisão de serviços de educação, saúde e previdência social.

Um segundo regime é de caráter liberal. Nele ocorre forte e acelerado deslocamento da ação estatal para a prestação privada de serviços em educação, saúde e previdência social. Para Franzoni (2005), México, Chile e Argentina estão nessa condição. A inversão pública por habitante, embora alta, reflete a combinação de regimes contributivos na previdência, com regimes focalizados na saúde e educação.

$\mathrm{O}$ terceiro regime de bem-estar latino-americano tem marcas de autonomia, nele o modelo de Estado social é informal com baixa capacidade institucional. As formas de provisão são múltiplas. Isto ocorre em Guatemala, El Salvador e Nicarágua. As mulheres têm que responder a alta demanda do seu papel informal e familiar como cuidadoras. Os países que praticam esse regime têm altos níveis de desigualdade, seus índices Gini têm incidência acima de 0,60.

Apresentei, como uma das contribuições para a Pré-Conferência Brasileira à Conferência Internacional de Bem-Estar Social (SPOSATI, 2008), a análise do conteúdo de Constituições de países latino-americanos quanto aos direitos sociais, com base no banco de dados da Universidade de Georgetown (2008). Essa análise mostrou que países da região mantêm sua responsabilidade social centrada na legislação social do trabalho. A cidadania é fragilmente afirmada como garantia de direitos humanos e sociais. A noção de seguridade social restringe-se à política contributiva da previdência social. No caso da Venezuela, o artigo 55 de sua Constituição faz menção direta ao apoio às situações de ameaça ou risco à integridade, especificando no artigo 86 a responsabilidade do Estado e afirmando que, a "ausência de capacidade produtiva não será motivo para excluir pessoas de sua proteção" (SPOSATI, 2008).

$\mathrm{Na}$ análise das políticas sociais latino-americanas, tenho me valido da construção da categoria regulação social $\operatorname{tardia}^{2}$ (SPOSATI, 2002). Essa categoria demonstra que as políticas sociais na região se conformam em um movimento histórico, distinto do europeu, marcado por características próprias de sua história, do seu estágio de desenvolvimento econômico no contexto mundial, pela hegemonia de forças políticas antidemocráticas, impostas pela força e violência de ditaduras militares. Nos países latino-americanos, as políticas sociais são instaladas de forma fragmentada, setorizada e em geral, com acesso limitado ao operariado urbano, e fortes sinais de branqueamento no acesso a seus benefícios.

Grande parte dos países latino-americanos ao propor políticas sociais buscou seguir modelos europeus, sem levar em conta suas marcas históricas quanto à presença da escravatura negra e da servidão indígena. Essas regulações seletivas produziram uma apartação social de tal gravidade, que impediu a constituição de sistemas latino-americanos igualitários como os experimentados pelas iniciativas europeias, abrangentes no reconhecimento dos direitos. Aliás é bom que se relembre que, neste século 21, alguns países europeus como a França vêm tomando medidas de segregação étnica ${ }^{3}$.

Os países da região, que manifestaram comportamento hostil aos afrodescendentes ou aos de ascendência indígena, instalaram sistemas de proteção social contributivos direcionados ao apoio da industrialização e ao trabalho formal no meio urbano, com predomínio do acesso a brancos. Uma grande distância ocorreu (e ocorre ainda) para a inclusão da população rural nos direitos sociais. Estimase que a população indígena na América Latina esteja entre 40 e 50 milhões e os afrodescendentes em 150 milhões. Estas populações são particularmente vulneráveis.

Somente no Uruguai e na Argentina, e na fase anterior às ditaduras, é que cresceu o alcance do sistema de proteção, uma vez que essas sociedades se aproximaram do pleno emprego.Todavia, sua regulação social foi baseada na condição do trabalho formal e não na cidadania. Portanto, sob o predomínio da regulação social do trabalho, que tem por centralidade a reposição da capacidade de consumo do trabalhador no mercado através de benefícios, a ênfase é a monetarização da política social mantendo, ao mesmo tempo, o poder de consumo do trabalhador e o fluxo da economia. Essa opção fica distante da política social como efetivadora de garantias sociais a todos os cidadãos através de redes quanti qualitativa de serviços públicos que provê atenções a todos os membros de uma família, respeitado seu estágio no ciclo vital e suas singularidades. 
Os Estados latino-americanos se ativeram até quase o final do século 20 à legislação social do trabalho e à educação e só nos últimos 20 anos é que ampliaram o alcance das políticas sociais para as áreas de saúde, habitação e assistência social, entre outras.

\section{Heranças do século 20}

O último quartil do século 20 teve associações perversas para a política social latino-americana, pois combinou dois grandes ingredientes contrários à extensão da agenda dos direitos sociais providos pelo Estado: as ditaduras militares e a subordinação ao neoliberalismo do Consenso de Washington. A autonomia dos Estados latino-americanos foi subordinada pela sua dívida externa ao FMI, impedindo o crescimento das responsabilidades públicas com o social, negadas pela prevalência do conceito de Estado mínimo.

De um lado, a superação necessária face ao arrocho salarial e a violência das ditaduras militares, com a redução do alcance das responsabilidades estatais com o social e, de outro, o confronto com a agenda neoliberal reforçadora do Estado mínimo foram marcas a enfrentar ao final do século 20 (HUBER,1996). A conjuntura de negação de direitos, trabalhistas ou sociais, a agudização do empobrecimento, o crescimento da desigualdade social, e a instalação da nominada "dívida social" foram fortes heranças do período.

Ocorreu a recentralização do social no mercado tornando-o locus privilegiado de ofertas sociais o que ampliou a privatização da educação, saúde, previdência social, assistência social, quer para o campo lucrativo, como para o não lucrativo. Enfatizo o não lucrativo ou filantrópico, valorizado pela regulação neoliberal, na medida em que acentua a não responsabilidade pública pela valorização das iniciativas da sociedade que não asseguram direitos sociais. O enquadramento neoliberal imposto pelo FMI aos países latino-americanos subordinou a ampliação da agenda pública ao mercado e à filantropia e configurou a oposição entre o Estado e os reclamos dos movimentos sociais.

Essa subordinação colocou uma questão política quanto à autodeterminação da agenda social de cada país. Estaria ocorrendo uma subordinação da autonomia dos povos à regulação internacional no âmbito do social? Haveria espaço para a autonomia nas políticas sociais de cada país face às regulações econômicas das agências internacionais? (DEACON, 2000).

Considero serem estas questões de relevância ao tratar das políticas sociais de uma região que foi historicamente subordinada aos centros econômicos mundiais. Em outros termos, cabe discutir se a agenda pública dos países latino-americanos nas políticas sociais está determinada pela globalização econômica ou se existem espaços e autonomia para construções nacionais? Conseguiram os países latino-americanos sob a gestão de governos democráticos fazer avançar políticas sociais que garantam direitos de cidadania? Com certeza, o avanço da política social sob governos democráticos é uma grande questão. Sua efetivação poderá desenhar novos tipos de Estados sociais latino-americanos para este terceiro milênio.

Tanto o Mercado Comum do Sul (Mercosul) quanto a União das Nações Sul-Americanas (Unasul) não demonstram intenção ou capacidade para desencadear força unitária no âmbito das políticas sociais. $\mathrm{O}$ desempenho das políticas sociais permanece no âmbito de cada país. No Mercosul, predominam os acordos sobre as relações econômicas entre os países e, na Unasul, o forte é o seu caráter político fortalecedor da autonomia latino-americana. Não temos ainda, uma unidade latino-americana articulada pela defesa de direitos humanos e sociais.

Não se dispõe na América Latina de locus de defesa de direitos sociais mesmo com a emergência de governos com agenda centradas em interesses democráticos e populares.

Os movimentos sociais, fortes nos anos 1980 e 90, e hoje mais diluídos, colocaram-se no âmbito da democracia social e política. Reclamaram e conquistaram, ainda que pontualmente, a introdução de novo formato participativo na gestão das políticas sociais, incorporado à descentralização e à presença da participação popular e do controle social. Embora o controle social ainda seja relativo, pode-se afirmar que ele cresceu na luta pela transparência na gestão de pleno acesso pela internet.

Esse novo formato participativo exigiu a descentralização da gestão de modo a possibilitar o exercício do controle social popular. É fato que essa descentralização colaborou com os desejos neoliberais de redução das responsabilidades do Estado central. Com a presença da globalização e o desmanche do modelo nacional-desenvolvimentista, onde o Estado nacional é que centralizava o gerenciamento de políticas sociais (mesmo que poucas ou frágeis), ocorreu a transferência de responsabilidades sociais para a gestão dos municípios. Esta passagem soou ao ideário neoliberal como uma redução da responsabilidade estatal. $\mathrm{O}$ aparato institucional gestor do município não era concebido como Estado propriamente dito. Dele não se esperavam responsabilidades assumidas como as do Estado central. Tradicionalmente este estatuto foi destinado ao órgão nacional. Aos movimentos sociais, o sentido da descentralização não descolava a função de Estado das gestões municipais. Pelo contrário, a gestão local ou municipal consistia no Estado próximo e palpável que se viu impelido a dar respostas soci- 
ais e, ao mesmo tempo, a pressionar outras instâncias de governo estatal a lhes dar apoio.

Para os movimentos, a desconfiança no Estado autoritário exigia novo formato de gestão participativa e descentralizada. A gestão local ganhou novo peso e presença só que mediada, muitas vezes, por organizações sociais o que, paradoxalmente, atendia aos reclamos participativos do processo de democratização e aos intuitos neoliberais de restrição da ação estatal direta. A ação pelos municípios diluía a responsabilidade nacional e proporcionava a fragmentação de experiências, pois respondia às demandas articuladas ou organizadas e não ao direito à satisfação de uma necessidade de todos os cidadãos que viviam naquela cidade, estado ou país.

Portanto, ao mesmo tempo, o Estado central reduziu suas responsabilidades em assumir novos compromissos delegando-os às gestões locais. Se, aparentemente, estava em curso um processo participativo ampliado, o limite dos orçamentos públicos municipais e sociais reduzia (e reduz ainda) as possibilidades reais de políticas públicas sociais universais que permitissem incluir a todos. Muitas novas experiências foram desencadeadas, mas sempre pontuais, sem condição de produzir a igualdade de possibilidades a todos que demandavam respostas às suas necessidades.

Não se constituiu a leitura da totalidade de demandas que ficou abafada pela esperança de algumas inclusões limitadas. A questão não era a superação da desigualdade e sim a demonstração de possibilidades reais de inclusão. Um outro mundo se mostrava possível por meio de algumas experiências e não pela sua universalização. Estes registros não são uma crítica a iniciativas como a do Fórum Social Mundial, mas a necessária interlocução de suas conquistas com a efetiva universalização dos direitos sociais e humanos.

A luta social e política não era marcada pelo predomínio do alcance amplo dos resultados, mas sobretudo, pelo modo de produção desses resultados sob a presença da participação, do controle social e da democratização das decisões. O controle social, a presença dos conselhos participativos de gestão, as demandas corporativas dos agentes institucionais sugavam a maioria das forças em luta. A batalha pelo desmanche do autoritarismo predominou.

Permaneceu a fragmentação de experiências que marcou as políticas sociais nos países latino-americanos desde os pioneiros na introdução das políticas sociais. Cada política social se desenvolveu como um universo em separado.

Neste cenário as ONGs, resultantes dos movimentos sociais, ganharam forte protagonismo, todavia, e perversamente, isto significou um certo descompromisso do Estado nacional, regional e local em ampliar seu quadro de agentes institucionais públicos. Não raras vezes ONGs passaram a ser par- ceiras na execução de respostas. Muitas delas consideravam que assim deveria ser, pois o Estado, e seus agentes institucionais, não sabiam e não tinham efetivas condições, ou compromisso, em realizar uma ação na direção dos interesses populares.

Por decorrência do enfrentamento ao autoritarismo no interior do Estado, uma herança para o século 21 foi a experiência real da gestão democrática do social, mas com uma insuficiente formação de agentes institucionais públicos. Com certeza, essa forma de travar a luta social trouxe novos protagonismos. Representantes de segmentos sociais, antes invisíveis, ocuparam a cena política, lugares no parlamento, principalmente em âmbito local.

Todavia, o movimento pela constituição democrática das políticas sociais, de alto significado para a retomada do Estado de Direito, não teve forças para confrontar a incrível desigualdade social no interior dos países latino-americanos onde os altos índices Gini permaneciam inamovíveis ou de lenta redução.

As liberdades políticas decorrentes dos regimes democráticos de direito continuaram a conviver paradoxalmente com a precarização e privação nas condições de vida e de viver de muitos.

A desigualdade, historicamente assentada desde a colonização dos países latino-americanos e não superada nos movimentos de independência, ou na sua conformação republicana, teve sua manifestação deslocada do campo das necessidades sociais (a serem providas por políticas sociais universais) para a atenção a necessitados sociais. Esse deslizamento encobria a cidadania e os direitos sociais por "boas ações" aos mais frágeis.

O jogo neoliberal do Estado mínimo desenhou nova acrobacia. Trata-se agora, de identificar os mais precarizados e criar formas de sua "melhoria social" ou redução de sua indigência e não de estender a todos as condições dignas de respostas às necessidades sociais como marca de reconhecimento da cidadania. O enfrentamento da desigualdade, cuja presença é de ordem fortemente econômica, passou a ser tratado no âmbito da ordem social. Por decorrência, a democracia, embora presente como reclamo dos movimentos sociais na gestão das políticas sociais, não alcançou abrangência ou velocidade a ponto de se confrontar com a desigualdade social e econômica que se manifestava (e manifesta ainda) na configuração das políticas sociais.

As políticas sociais por sua restrita cobertura ou pela diferenciação de padrões de acesso e inclusão (entre uma e outra política social) são geradoras de desigualdades entre os cidadãos no alcance de seus direitos de cidadania.

O jogo entre a ordem econômica e social, somado a distância entre os direitos formais e os reais, refreou a possibilidade da leitura da totalidade das demandas da sociedade. Este é o momento da con- 
versão das políticas sociais de direitos em políticas de combate a pobreza que se voltam para a redução da miséria sem alcance de direitos sociais.

A proposição do IDH em 1990 confrontou a falsa construção do PIB per capita, mas terminou por centrar forças nas piores situações (analfabetismo, baixa escolaridade, baixos ingressos, baixo índice de longevidade, e o despreparo da mulher). Sem dúvida, situações indignas, mas que terminaram por centrar, ou no termo neoliberal focalizar, as necessidades sociais como manifestação de alta precarização, sem apontar seu contraponto com a alta acumulação, demarcando os níveis de desigualdade social existentes.

Políticas de combate/superação/erradicação da pobreza, da extrema pobreza ou da miséria tenderão a ser focalistas e emergenciais, como propõe o velho rito neoliberal, caso não se articulem com mecanismos redistributivos que alterem a alta acumulação ou concentração de riquezas. Combater a miséria e a pobreza implica em política econômica e não só social. Supõe o enfrentamento de desigualdades sociais que se expressam, inclusive, nos acessos das políticas sociais tradicionais.

A alarmante precarização, ou desapropriação das condições de vida e de viver, passa a exigir novas respostas das políticas sociais consideradas fundamentais, como educação e saúde. Não basta a educação propor a escola, a condição do docente ou a disponibilidade de vagas em salas de aulas. É preciso afiançar condições para que se dê a presença do aluno. É preciso construir o acesso a transporte escolar, alimentação, material escolar, uniforme, pois o baixo poder aquisitivo das famílias não possibilita essas (pré)condições. Torna-se necessário desmercadorizar condições que permitam a frequência à escola, isto, todavia, não pode significar uma ação discriminatória da política setorial direcionada aos mais pobres. O mesmo ocorre na saúde. Não basta ter a Unidade Básica de Saúde ou ter a presença do médico. É preciso ter o acesso a medicamentos, a nutrição e a próteses.

Dois desafios se colocam à universalização de políticas sociais tradicionais em contexto de desigualdades sociais: precisam se expandir em quantidade e qualidade, mas também, desmercadorizar condições de serem acessadas e efetivadas. Isto é, a operação da política precisa atentar para as condições objetivas de vida dos usuários dos serviços para que possam de fato, contar com os procedimentos desses serviços. Não existem condições para que indivíduos ou famílias sejam provedores de pré-condições de políticas sociais. É preciso romper com os dispositos pelos quais a família (leia-se mulher) é quem exerce a gestão de acessos parcelares de seus membros a diversos programas e políticas, substituindo a coerência entre as políticas públicas.

O alongamento da atenção de cada política social para novos segmentos de trabalhadores precarizados e desprovidos de acesso a condições básicas é por vezes operado de forma apartada. Isto é, como uma política a parte para atender a indigentes e pobres. Por vezes, o modelo de gestão desloca a atenção às (pré)condições para o campo da assistência social, caracterizando-a como espaço de apartação dos precarizados. Nessa situação, essa possível política pública de direitos se transforma em mecanismo de apoio, processante de condições "para indigentes e pobres frequentarem as políticas fundamentais". Alguns defendem, inclusive, que a assistência social deva se conformar como uma política auxiliar das demais, isto é, um mecanismo mediador de acesso, e não uma política social de direitos.

A construção do Sistema Único de Assistência Social (SUAS) vai em direção oposta a essa concepção e estabelece provisões próprias da assistência social. O âmbito desta política como campo de direitos é, ainda, um campo de luta contra aqueles, de direita ou esquerda, que a caracterizam de forma desqualificada como assistencialista ou compensatória. A democratização das políticas sociais exige atender a todos, o que inclui os mais precarizados. Há ainda em voga a concepção (talvez elitista) que toma essa extensão como deterioração da política social chegando a nominar essa ocorrência de "assistencialização da política social". Análises latino-americanas aplicam o designativo político "assistencialização da política social", no sentido de mostrar a focalização da política aos mais pobres (SOTO; TRIPIANA, 2009). Seja em uma ou outra forma, ocorre uma crítica à assistência social, negando-a enquanto política de direitos sociais.

Sem dúvida, todos deveriam ter condições básicas e dignas de vida. Mas, também, as políticas sociais deveriam ser provedoras das condições implícitas nos resultados de seus serviços e atenções, sem que, para tanto, dependam do mercado ou do poder aquisitivo do usuário. Ampliar a cobertura das políticas sociais aos cidadãos passa, necessariamente, pela aproximação dos procedimentos de inclusão das políticas sociais às condições concretas de vida desses cidadãos.

Acesso à infraestrutura, como energia elétrica, água, coleta de lixo, coleta de esgoto, passa a compor o quadro das urgências sociais. Em áreas de seca, contar com açudes, transporte, e luz elétrica, são exigências para a extensão do acesso a melhores condições de vida.

O acesso ao alimento ainda se apresenta no século 21 como uma das lutas para ampliar a produção e sua distribuição às demandas, de modo a oferecer segurança alimentar.

A promoção de segurança alimentar na América Latina e Caribe está diretamente ligada ao campo, onde se localiza a metade da população indigente da região. 
Das 53 milhões de pessoas que atualmente sofrem de fome na região,entre $15 \%$ e $20 \%$ são crianças menores de cinco anos de idade, cujo crescimento e desenvolvimento serão prejudicados se elas não tiverem acesso a uma alimentação adequada. $\mathrm{Na}$ Guatemala, na Bolívia, no Peru, em Honduras, no Haiti e no Equador, a subnutrição infantil crônica afeta mais de $30 \%$ das crianças (FAO, 2009, p. 3-6).

A redução de assimetrias no acesso a recursos, como terra e água, maquinário e tecnologia para fomentar a produção, torna-se urgente no confronto das desigualdades entre o urbano e o rural.

Pode-se dizer que o grau de destituição dos povos latino-americanos trouxe como exigência não só a introdução de respostas sociais, mas também a urgência de acesso aos meios para que possam ser incluídos nessas respostas quando existentes. Não se torna factível propor políticas sociais sem levar em conta as condições objetivas da população que será sua usuária (SPOSATI, 2009).

O lineamento das políticas sociais tende a se aproximar da legislação social do trabalho e da vida do trabalhador formalmente assalariado. $\mathrm{O}$ pacto que sustenta essas políticas não ocorre em direção a todos os cidadãos, o que incluiria reconhecer o estatuto de destituição em que se encontram. Recortam a sociedade pelo fio dos trabalhadores formais. Os demais permanecem apartados.

Por essa leitura, baseada na prevalência do trabalho formal, como se fosse real o pleno emprego, os dispositivos das políticas sociais partem de supostos como: a existência de uma família onde a mulher permanece em uma casa, com água, luz, alimentação, acesso à informação etc. O real, todavia, é a luta por um lugar para morar, luta pela instalação de energia elétrica, rede de água, rede de esgoto.

Uma alternativa de gestão, adotada com o objetivo de criar uma dualidade de cobertura para os mais pauperizados, ocorre pela mediação de entidades sociais substituindo a possibilidade do direito social pela benemerência ou filantropia.

Outra herança da gênese das políticas sociais latino-americanas que alcança o século 21 é a ausência de articulação, intersetorialidade entre as áreas de ação de cada uma das políticas sociais. A institucionalização setorializada e fragmentada das políticas sociais mostra seu limite na operação em contextos de desigualdades sociais. A intersetorialidade na operação das políticas sociais torna-se uma exigência pela necessária interdependência das coberturas de atenções de cada política social (SPOSATI, 2006b).

A emergência e a institucionalização de cada política social ocorreram em tempos e marcos próprios à conjuntura sociopolítico-econômica de cada país. Mais ainda, a maturação do conhecimento científico, as diretrizes do grupo no poder, o peso da corporação hegemônica, os movimentos das demandas impactaram o desenho de cada uma delas. As políticas sociais setoriais tendem a constituir universos e culturas próprias que terminam por estabelecer barreiras de articulação na oferta e na dinâmica dos serviços na ponta, ou na relação com a população.

Outra questão fundamental e nova diz respeito ao debate intersetorial sobre a universalidade, ou universalismo, estendido ao conjunto das políticas sociais. Em outros termos, o caráter setorizado das políticas sociais, a partir de referências próprias, coloca impedimentos à interdependência dos acessos entre elas. Essa questão se torna mais evidente com a aplicação de análises territorializadas das demandas e do alcance das respostas das atenções de cada política social.

A leitura territorial das condições de vida do cidadão vem se mostrando útil à necessária ampliação de cobertura de cada política social e a intersetorialidade entre as ações das políticas. Não é fato que a abordagem territorial nas políticas sociais fragmenta a leitura da realidade e, com isto, dissolve a perspectiva crítica de totalidade. A leitura territorial não tem por propósito o localismo e, sim, a relação concreta com as condições de vida real daqueles que estão nos territórios. A análise territorial restringe rotas de fuga da desigualdade real e impede leituras que centram responsabilidades no indivíduo, como se fosse o responsável pela dívida social que o vitimiza.

\section{Desafios do século 21}

O maior desafio do século 21 é o de reposicionar o lugar das políticas sociais no enfrentamento das desigualdades sem se transformar em paliativos à pobreza, gerando atenções de segunda categoria.

Outro grande desafio é a incorporação nas políticas sociais tradicionais, como saúde e educação, das demandas de direitos humanos e de direitos sociais, voltadas para gênero, ciclo de vida (crianças, adolescentes, jovens, adultos, idosos), pessoas com deficiência, por ascendência étnica, culturais, para necessidades especiais, entre outras. Trata-se da introdução do campo da equidade no âmbito das políticas sociais, cuja matriz é pautada principalmente na igualdade. A universalidade passa a pressupor a composição entre as garantias de igualdade e de equidade. Há aqui um forte imbricamento com as políticas de defesa de direitos de proteção social.

A universalidade põe em questão não só a dimensão da demanda atendida e da reprimida, mas também o alcance de resultados nas políticas sociais. Este processo exige alcançar a diversidade na entrada dos serviços e a equidade nas respostas ou na saída da atenção e dos cuidados prestados. 
Esse conjunto de situações somadas à tradição do universalismo sem universalidade do século 20 vai trazer novas demandas a serem incluídas no âmbito das políticas sociais, bem como uma concepção de universalismo que faça o diálogo entre as diferentes políticas sociais, seus acessos e a perspectiva da equidade.

Ao final do século 20, por decorrência do Estado mínimo, houve uma redução do alcance de políticas sociais e sua transmutação em políticas de combate à pobreza. Claro que há aqui uma mistificação, entendendo que uma política social possa superar a pobreza. A pobreza é uma questão multidimensional, ou uma questão lastreada no modelo econômico e não do alcance da política social.

O debate social focado na pobreza destitui a condição de direito e cidadania. Somente quando as causas da pobreza forem criminalizadas é que de fato se poderá discuti-las como violação de direito humano. Por adotar essa perspectiva é que se destacou a diferença que é tornar cada política social alcançável a todos, independentemente de sua condição real, e não a de constituir atenções paralelas aos mais pobres.

Volta-se a chamar atenção para o comportamento de culpabilização do indivíduo pobre pela sua pobreza, descolando-o das condições reais que determinaram sua situação. O trabalhador pobre ocupa empregos precários cujos salários não permitem superar as condições em que vive. Sua vulnerabilidade resulta também da subordinação ao trabalho precário. O que se quer apontar é que o enfrentamento da miséria ou da pobreza não se dá somente pela renda do trabalho, mas por um conjunto de suportes que envolve a presença e qualidade de políticas públicas. Tem-se aqui duas frentes, a precariedade do trabalho e a ausente proteção social, como reforçadoras da superação da pobreza.

A redução da política social ao conceito de política de combate à pobreza provocou uma transmutação: a prestação de serviços foi substituída pela monetarização de benefícios. Tem-se aqui uma alteração da materialização das políticas sociais. Ela se torna ao mesmo tempo apoio ao beneficiário e investimento na circulação de mercadorias. A aplicação do benefício se dá no mercado e, pela incidência de impostos regressivos nas mercadorias (quem menos tem, paga mais), uma parte do benefício retorna ao Estado na forma de taxações. Uma das mãos estende e a outra recolhe. Portanto, a monetarização da política social tende a ser mais uma política econômica com efeito social pela ampliação das condições de consumo. O gerenciamento de políticas monetárias é similar ao da gerência financeira. A relação direta entre o agente institucional e o requerente se dá no momento de preencher cadastros e apresentar documentos. A partir daí, a gestão de cadastros, o banco de dados, a seleção para inclusão e controle de re- sultados ou condicionalidades ocorrem por ferramentas informatizadas e cartões plásticos.

Os agentes institucionais são solicitados para o desempenho de novas funções na informatização da gestão, sendo reduzida sua participação no processo de atenção direta.

O cidadão fica secundado ao indivíduo que deve ser fornecedor de dados, documentos e um agenciador de atenções de diferentes serviços públicos para cumprir condicionalidades. A monetarização da política social passa a dar papel secundário ao agente social e seu papel educativo e faz sobressair sua função de distribuidor de benefícios por critérios programados. Ele passa a ser mais um informante do sistema informatizado sem interferência sobre as decisões do programa eletrônico. Seria uma forma de robotização do social?

A Previdência Social em sua trajetória histórica perdeu sua função de ser responsável pela provisão de diversas necessidades do trabalhador, como condições habitacionais, de alimentação, de saúde, de lazer, entre outras. Na sua condição inaugural ela era a política social e não uma das políticas sociais. Com o desenvolvimento das demais políticas sociais, ela vem se tornando cada vez mais uma política monetarizada, com gestão dentro desses padrões. Exemplo típico no Brasil é a gestão do salário família. Como sua operação se dá pelo empregador que presta contas à Previdência Social, nada se sabe sobre as crianças e os adolescentes filhos dos trabalhadores abrangidos pelo salário família. Esse modelo é aplicado em outros países latino-americanos.

No modelo de monetarização da política social ocorre a mercadorização da atenção. O benefício tem por efeito a dinamização da economia através do mercado. Muito já se discutiu sobre a distribuição de tíquetes, vales para obter alimentação, serviços de saúde, entre várias alternativas de substituição do acesso em bens ou em condições de aquisição no mercado.

Com certeza estamos diante do fenômeno da financeirização do social que toma o mercado como o grande agente regulador. De fato, estamos diante de um novo avanço de campo da acumulação capitalista. O que põe em dúvida se a monetarização do social é, de fato, já que não é de direito, uma política econômica capitalista ou uma política social de enfrentamento de desigualdades?

A via mais atual, em toda a América Latina, é a de combinação da política de combate a pobreza com a monetarização da política social através dos programas de transferência condicionada de renda (PTCR).

Esta via se distingue de outra em curso que propõe a renda universal de cidadania, objeto de rede internacional, que tem no belga Van Parijs um de seus precursores e é nominada Basic Income Earth Net (BIEN). Dela fazem parte o argentino Ruben Lo 
Vuolo e o senador Eduardo Suplicy, do Brasil, entre muitos outros.

Os PTCRs têm sido objeto de múltiplas experiências como o Progresa/oportunidades, no México (2000); Chile Solidário/Puentes (2002), no Chile; o Bolsa Família (2003), no Brasil; o Plano de Assistência Nacional a La Emergencia Social (Panes), do Uruguai; o Asignacion Universal per Hijo (AUH, 2009), na Argentina. Cada um tem suas peculiaridades e possibilidades no apoio às famílias empobrecidas para a educação de seus filhos.

Em muitos países, a alocação familiar é um direito a partir do segundo filho e é considerada uma contribuição necessária à igualdade de condições na educação das crianças.

$\mathrm{O}$ crescimento da via monetarizada da política social coloca em questão o financiamento da expansão e qualificação dos serviços. A relação serviçosbenefícios precisa ser construída sob pena de a política social transformar-se na co-gestão de cartões plásticos de forma integrada ao setor bancário.

A expansão dos serviços retoma, no século 21, a velha questão da combinação entre provisão pública estatal e atenções privadas de entidades sem fins lucrativos que pretendem financiamento público. A responsabilidade pública volta a ficar embaraçada nesta teia que provoca uma retração de direitos sociais e dever estatal. Por outro lado, algumas ONGs, isto é também entidades não lucrativas, permanecem em luta com o Estado na exigência de cumprimento de direitos sociais. Esta complexidade do campo não lucrativo (que se quer público não estatal) exige novas formas de regulação de modo que relações de parceria não signifiquem perdas de direitos sociais ou recuo, quer da responsabilidade do estado quer da fiscalização da sociedade civil.

Iniciativas não lucrativas da sociedade civil podem encobrir a exigência de incorporação das atenções na agenda pública para que se tornem direitos sociais.

Outra dimensão, própria do século 21, que afeta as políticas sociais é a articulação entre direitos humanos e sociais que exige a convergência de pautas. No movimento social há, por vezes, a concepção, que considero enganosa, de que os direitos humanos são éticos e revolucionários e os direitos sociais reformistas e enganosos. As lutas de gênero, deficiência, etnia, ciclo de vida são transversais às políticas sociais. Nesse sentido, áreas de gestão governamental criadas para atenção a gênero, etnia, idoso, criança e adolescentes etc. ganham presença como controle social das demais políticas, o que gera conflitos de gestão. Os serviços estruturados como respostas a necessidades sociais, no âmbito de políticas setoriais, tendem a uma dificuldade em se adaptar a demandas transversais. Tem-se aqui uma zona de conflito entre segmentos sociais e necessidades sociais no desempenho das políticas sociais.
Outro desafio ainda presente não só no Brasil mas em outros países latino-americanos é o deslizamento da responsabilidade estatal pelo social para o âmbito das esposas dos governantes, as primeiras-damas. Esta estratégia desloca o "possível" direito social não só para o campo da benemerência como do patrimonialismo da política do favor. Pior ainda é que esse embaraçamento público/privado (quase intimista) reafirma uma negativa feminilização do social, repassando a responsabilidade da administração direta, gerida pelo governante, para o coração da sua esposa que opera com recursos públicos, fora das regras públicas.

A questão de gênero é importante na decodificação do social. Uma de suas expressões se dá pela feminilização da pobreza e, com isto, uma centralidade da relação dos programas sociais com a mulher enquanto provedora de cuidados. No imaginário, a mulher é considerada mais confiável, menos praticante do desperdício, mais vinculada à proteção da família e da criança.

As desigualdades raciais são também uma das dimensões a enfrentar nas políticas sociais, principalmente pelo fato de que na maioria dos países latino-americanos foram instaladas sob o padrão de branqueamento dos usuários. A multicultura e a etnia dos povos latino-americanos exigem que políticas sociais confrontem o preconceito e a discriminação.

Há, ainda, outra dimensão a ser destacada. As políticas sociais setoriais desenvolvem seu olhar para o indivíduo, o cidadão que está num certo momento do ciclo de vida. Todavia, a articulação das atenções das políticas sociais se dá no marco da família. Franzoni (2005) considera que a família opera uma ação reequilibradora das formas assimétricas com que o Estado e o mercado incluem cada um de seus membros. A família endogeniza as presenças e ausências de apoio das atenções das políticas sociais, através de seu trabalho e de suas relações parentais, vicinais e sociais. Opera a divisão sexual do trabalho e dos cuidados que tendem a sobrecarregar a mulher. Ela termina por constituir o locus do regime de bem-estar em operação.

Cresce a incidência da chefia feminina nos domicílios, colocando em questão se a responsabilidade uniparental garante, ou não, os níveis adequados de cuidados de proteção social na família. Outra tendência é a de remunerar o trabalho da mulher como cuidadora da unidade familiar, para além de trabalhadora formal ou informal. A mediação da mulher nas demandas da dinâmica familiar e a sobrecarga de seu trabalho têm levado a intensificar propostas de desfamiliarização de alguns cuidados, passando sua provisão para programas sociais. São exemplos, os centros dia para apoio a idosos, a pessoas com deficiência, creches, entre outras atenções infantis que permitem a frequência a dia. É preciso objetivar a dimensão real da capacidade protetiva das famílias de baixos salários. 
A desfamiliarização significa reduzir a carga da família na provisão de cuidados e não de aumentálos. A familiarização segue caminho oposto. Por exemplo, demanda da mãe que cumpra as condicionalidades de um programa, ou procedimento, sem verificar suas condições objetivas para operá-lo. Nesse caso, aumenta a carga da família retirando a responsabilidade do Estado.

Como se percebe, convivemos com incertezas, oscilações nas alternativas das políticas sociais para o século 21. O que se percebe é que quanto mais precarizada a vida do cidadão e de sua família, mais o caráter especializado de uma política social se lhe apresenta como barreira ao acesso e inclusão.

Um novo desafio que vem se manifestando é a existência de intervalos de cobertura das políticas sociais. A alternativa de combate à pobreza, ao operar por seletividade de meios e estabelecer limites por faixa de renda, gera a ausência de cobertura àqueles que são limítrofes (board line) à condição, embora tenham necessidade significativa de acesso.

A análise comparada da cobertura da política de proteção social contributiva com a não contributiva permite identificar "gaps" de atenção. O avanço da política de proteção social exige a interrelação entre suas formas contributivas e não contributivas. Este desafio decorre não só pelo crescente envelhecimento, mas também pelas restrições impostas pelo neoliberalismo às formas de benefícios no sistema contributivo.

Nesse conjunto há que se discutir o novo sindicalismo como a Central de los Trabajadores Argentinos (CTA), o movimento sindical PITCNT no Uruguai e as centrais sindicais brasileiras quan-

to às suas demandas para a política de proteção social. Instalou-se no Brasil a Confederação Nacional dos Trabalhadores em Seguridade Social (Cntss), que vem provocando o debate conjunto entre saúde, previdência social e assistência social. Trata-se da unificação de propósitos entre os trabalhadores que terminam por viabilizar a cultura da intersetorialidade.

\section{Considerações finais}

Esta reflexão partiu da afirmação de que as políticas sociais são vias de duas mãos, entre capital e trabalho e a hegemonia do Estado. Percebe-se a crescente incorporação de demandas sociais pelo Estado, mas essa inclusão, não raras vezes, dá-se de forma articulada aos interesses de acumulação do capital e, nas políticas de transferência de renda, em apoio ao capital financeiro. É de se questionar, ainda, se essa incorporação vem se dando, ou não, por meio de formas precarizadas que não consolidam a condição da cidadania ou dos direitos sociais combinados aos direitos humanos.

Uma das avaliações que se faz no Brasil é que o traço democrático-popular do governo Lula desencadeou em quase todos os ministérios nacionais a expansão da atenção das políticas sociais para segmentos populares antes invisíveis aos olhos do Estado - são os quilombolas, as populações ribeirinhas, os pequenos grupos extrativistas ou as formas de agricultura familiar, entre outros. Ocorreu uma expansão do acesso à documentação, à energia elétrica, ao crédito e à ampliação da renda familiar. Isto vem permitindo nova condição de reconhecimento social e de pertencimento (SPOSATI, 2010).

Acesso, visibilidade, equidade entre rural e urbano passaram a ser uma nova aquisição que, junto com a participação democrática, constituem elementos formatadores da dinâmica das políticas sociais. Todavia, é preciso avançar em padrões de alcance dos resultados dessas políticas no campo dos direitos humanos e sociais.

Com certeza, a América Latina, que é qualificada como a região mais desigual do mundo (o que é diverso de ser a mais pobre), caminha significativamente em seu processo de democratização e ruptura com a violência política. Cresce sua capacidade de consumo, mas não cresce no mesmo ritmo o trabalho digno. Há na região formas combinadas que são ao mesmo tempo paradoxais, principalmente para a concretização da cidadania e dos direitos humanos e sociais.

É preciso politizar a política social para que se possa continuamente avaliar seus caminhos e sua direção.

\section{Referências}

DEACON, B. Social Policy in a Global Context. In: HUMELL, A.; WOOD, N. (Ed.). Regulation, Globalization and World Politics. London: Open New Press, 2000, p. 211-247. 
ESPING-ANDERSEN, G. The Three Worlds of Welfare Capitalism. Princeton: Princeton University Press, 1990.

FAO - Organização das Nações Unidas para Agricultura e Alimentação. Panorama de la seguridad alimentaria y nutricional en América Latina y el Caribe. Escritório Regional da FAO, 2009. Disponível em: <http://www.r/ c.fao.org/es/prioridades/seguridad/panorama.htm $>$. Acesso em: 17 set. 2010.

FRANZONI, J.M. Regimenes de bien estar en América Latina: consideraciones generales e itinerários regionales. Revista Centro-Americano de Ciências Sociales, v. II, n. 2, p. 41-77, dic. 2005.

HUBER, E. Option for Social Policy in Latin America: Neoliberal versus Social Democratic Models. In: ESPINGANDERSEN, G. (Ed.). Welfare States in Transition. National Adaptations in Global Economies. London: Sage Publications/Unrisd,1996, p. 141-191.

MESA-LAGO, C. Models of Development, Social Policy and Reform in Latin America. In: MKANDAWIRE, T. (Ed.). Social Policy in a Development Context. Basingstoke: Unrisd/Palgrave Macmillan, 2004, p. 175-202.

SPOSATI, A. Regulação Social Tardia: características das políticas sociais latino-americanas na passagem entre o segundo e o terceiro milênio. Caderno Ideação, II Fórum Social Mundial, Porto Alegre, p. 33- 53, 2002.

Revista Sociales, v. I, p. 51-68, São Paulo,

2002

In: CONGRESSO INTERNACIONAL DO

CLAD, IX. Anais... Lisboa, 2002. Disponível em: <www.clad.org/congresos/documentos $>$. Acesso em: 6 abr. 2010.

Néoliberalisme et régulation sociale tardive: le modèle e etat social latino-américain. In: JOURNÉES DE L'ASSOCIATION D'ECONOMIE SOCIALE, XXIII, 2003, França, L’Harmatan. Anais... 2003.

Pobreza e desigualdade no século do desperdício. Debates Sociais, Rio de Janeiro: Cbciss, ano XLI, n. 65-66, p. 9-46, 2006a.

Gestão pública intersetorial: sim ou não? Comentários de experiência. Serviço Social \& Sociedade. São Paulo: Cortez, ano XXVII, n. 85, p.133-141, 2006b.

Proteção social na América Latina em contexto de globalização. In: PRÉ-CONFERÊNCIA BRASILEIRA PREPARATÓRIAà $33^{\mathrm{a}}$ Conferência Global de Bem-Estar Social do ICSW. Anais... Rio de Janeiro, 2008.
. Seguridad ciudadana: los múltiples desafíos para la institucionalidad social de América Latina. In: FLEURY, S.; SUBIRATS, J.; BLANCO, I. Respuestas locales a inseguridades globales. Fundación Cidob, Barcelona, 2009, p. 305-346.

O desafio da universalidade. In: GUIMARÃES, J. As novas bases da cidadania: políticas sociais, trabalho e previdência social. São Paulo: Fundação Perseu Abramo, 2010, p. 34-41.

SOTO, S. F.; TRIPIANA, J. Políticas sociales, trabajo y trabajadores en el capitalismo actual. Buenos Aires: Espacio Editorial, 2009.

UNIVERSIDAD DE GEORGETOWN. Base de datos políticos de Las Américas. Seguridad, prevision y assistencia social. Centro de Estúdios Latinoamericanos. Disponível em: 〈http://pdba.georgetown.edu $>$. Acesso em: 18 abr. 2010.

\section{Notas}

1 Os 20 países são: Argentina, Bolívia, Brasil, Chile, Colômbia, Equador, Paraguai, Peru, Uruguai, Venezuela, na América do Sul; Costa Rica, Cuba, El Salvador, Guatemala, Haiti, Honduras, Nicarágua, Panamá, República Dominicana, na América Central e, ainda, o México.

2 A categoria regulação social tardia foi pela autora apresentada em caráter inaugural, no II Forum Social Mundial de 2002, Porto Alegre. A seguir, foi discutida em encontro latinoamericanoem Washington, promovidopelo Indes/BID (2002), apresentada no IX Congresso do CLAD, em Lisboa (2002) e na XXIII Journées de l'Association d'Economie Sociale, em Grenoble/França (2003). Os artigos foram publicados noBrasil (2002), no site do CLAD, na Argentina (2002) e França (2003) e constam da bibliografia.

3 As lutas em diferentes países europeus mostram não só a intolerência com a migração mas o retrocesso com direitos conquistados no campo da previdência social, principalmente. Lembremos dos jovens franceses, filhos de migrantes, queem marçode 2009 naperiferia parisiense fizeram um forte movimento contra a discriminação a seus direitos já que nascidos em solo francês.

\section{Aldaiza Sposati}

aldaiza@sposati.com.br

Doutorado em Serviço Social pela Pontifícia Universidade Católica de São Paulo (PUC-SP)

Pós-Doutorada pela Faculdade de Economia da Universidade de Coimbra

Professora titular da PUC-SP 
Pontifícia Universidade Católica de São Paulo

Rua Monte Alegre, 984

Perdizes

São Paulo - São Paulo

CEP: 05014-901 